\title{
Post-impact flexural capacity of UHPFRC plates
}

\author{
Candida Talone ${ }^{1,2}$, Radoslav Sovják ${ }^{2,},{ }^{*}$ Michal Mára $^{2}$, and Jindřich Fornůsek ${ }^{2}$ \\ ${ }^{1}$ Department of Engineering and Geology, University of Chieti-Pescara, 66100 Pescara, Italy \\ ${ }^{2}$ Faculty of Civil Engineering, Czech Technical University in Prague, 16629 Prague, Czech Republic
}

\begin{abstract}
This work aims to demonstrate the effective use of fibre reinforcement in thin plate elements made of UHPFRC under projectile impact loading. The use of fibre reinforcement is very efficient in case of ballistic loading, as fibres are evenly distributed over the entire volume of the material body and possible damage to the plate is thus suppressed in all points of the plate element equally. The aim of this study is therefore to provide data on the residual flexural capacity of plates that have been significantly damaged by the impact of the projectile and to demonstrate the benefits of using fibre reinforcement for localized impact loading.
\end{abstract}

\section{Introduction}

Concrete is a material that has been used for ballistic protection for decades. With the development of building chemistry and dispersed fibre reinforcement in the form of microfibres, development and research in the field of concrete structures has reached ultra-highperformance fibre-reinforced cementitious composites (UHPFRC), which have a very high ability to absorb and dissipate mechanical energy at different strain rates. This is primarily determined by the use of fibrous reinforcement, which slowly begins to be pulled out of the cement matrix when the micro-cracks are opened, thus consuming a large amount of mechanical energy [1]. However, the biggest advantage of fibrous reinforcement is its even distribution over the volume of the examined element. This fact is essential from the point of view of terminal ballistics because the projectile can hit an element in virtually any place. This ensures the uniform resistance of the ballistic element in its entire volume, which is a clear advantage over conventional concrete bar reinforcement. Previous research on the dynamic testing of high-performance fibre-reinforced concrete and foam concrete is described in $[6,7,8,9]$.

\section{Materials and methods}

For this study, UHPFRC plates were tested, which are the basic elements of the ballistic system [2] and which are equipped with $1.5 \%$ fibrous reinforcement of the volume. The concrete composition is fully described elsewhere [3]. The UHPFRC plates were made from the same mixture but in two different places. In the first case, the plates were made in a

* Corresponding author: sovjak@,fsv.cvut.cz 
laboratory at the CTU in Prague and, in the second case, the plates were made in an industrial unit. The difference between them was easily comparable due to the shape of the edges, as in the case of industrial unit-made plates, the plates had chamfered edges.

Table 1. Specimens' casting places and status.

\begin{tabular}{|c|c|c|c|c|c|}
\hline Specimen & Casting place & Status & Specimen & Casting place & Status \\
\hline Slab01 & Industrial unit & undamaged & Slab05* & CTU lab & *damaged \\
\hline Slab02 & CTU lab & undamaged & Slab06* & Industrial unit & $*$ damaged \\
\hline Slab03 & Industrial unit & undamaged & Slab07* & Industrial unit & *damaged \\
\hline Slab04 & Industrial unit & undamaged & Slab08 & Industrial unit & undamaged \\
\hline
\end{tabular}

When the projectile hits the concrete specimen, in addition to the material compaction on the front side (Fig. 1), a pressure wave propagates and rebounds from the distal face of the plate, which can result in material scabbing from the backside of the sample. If the kinetic energy of the projectile is significantly greater than the energy that the element can dissipate, a total perforation of the specimen occurs, and the projectile embosses a truncated cone-shaped material from the back (Fig. 2).

Ballistic loading was in the framework of this study performed with a calibre $7.62 \times 51 \mathrm{~mm}$ full metal jacket bullet with a steel hard core. The bullet mass and velocity were $9.8 \mathrm{~g}$ and $820 \mathrm{~m} / \mathrm{s}$, respectively. The calibre of the projectile was used intentionally large enough to cause compression of the material on the proximal face together with the formation of the front crater, but also the scabbing of the rear crater on the distal side of the UHPFRC plate.
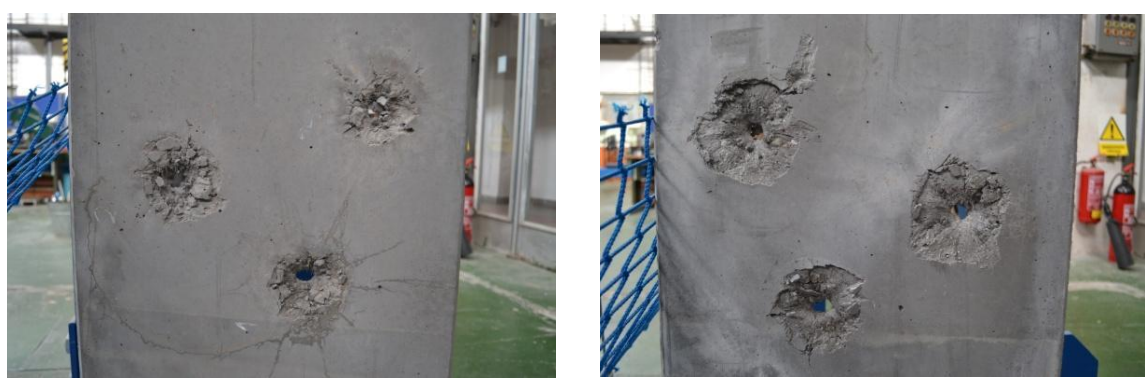

Fig. 1. Differences between projectiles' entrance (on the left) and exit (on the right) side.
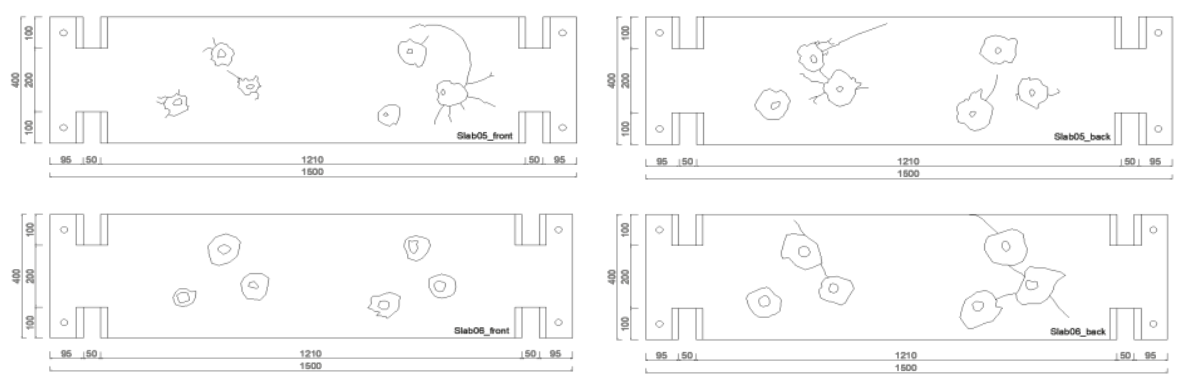

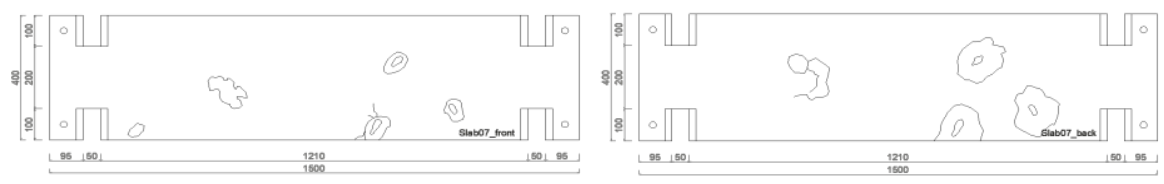

Fig. 2. Schematic of the entrance side (on the left) and the exit side (on the right) for each specimen.

The loading to determine the post-impact flexural capacity of the plates was performed by a hydraulic loading machine with a prescribed deformation of $1 \mathrm{~mm} / \mathrm{min}$. In the middle of the span, one draw-wire displacement sensor was mounted on each side and the average of both readings was plotted. The quasi-static load scheme was set for a clear span of $1260 \mathrm{~mm}$ and the loads were placed in thirds.

The plates damaged by the impact of the projectile were laid with the impact side facing upwards. This configuration may well represent the case where the impact of a projectile is followed by a blast pressure wave. In this case, the projectile can be replaced by a shrapnel or a secondary fragment, which is also an object with high speed and relatively low weight, causing predominant local damage [4] before the shock pressure wave occurs (Fig. 3).

\section{Results and discussion}

The result of the flexural loading tests is the determination of the load-displacement diagram of UHPFRC plates. The load-deflection diagram of the reference samples consists of three major phases. The first phase is a linearly elastic branch, which is characterized by the deformation of the material without the formation of cracks. After the cracks appear, the second part occurs, which is the strain-hardening of the material. This phase is characterized by increasing tensile capacity with increasing deformation of the sample and the development of the micro-cracks. After reaching the maximum load, one crack is localized and tensile softening occurs, which is characterized by a decreasing capacity of the bent element with increasing deformation. In this phase, all the deformation is concentrated in a single crack, where the individual fibres are pulled out of the sample matrix. The mechanical energy is significantly dissipated during this phase.

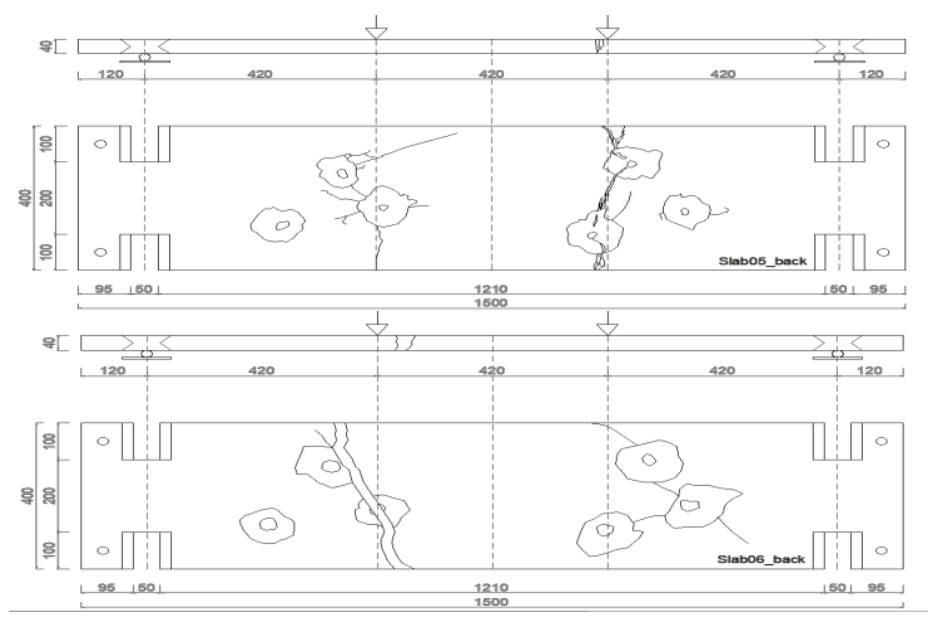




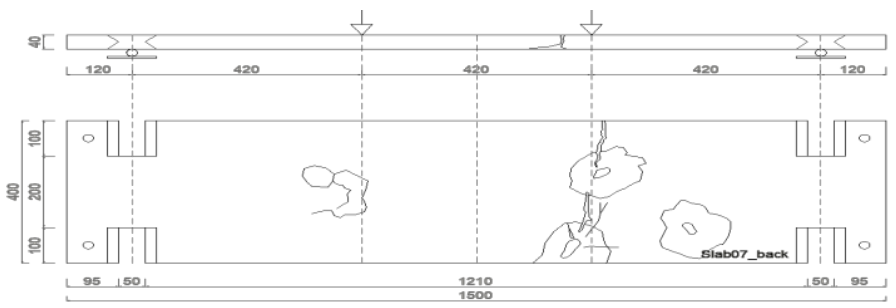

Fig. 3. Schematic of the damaged samples after the flexural test.

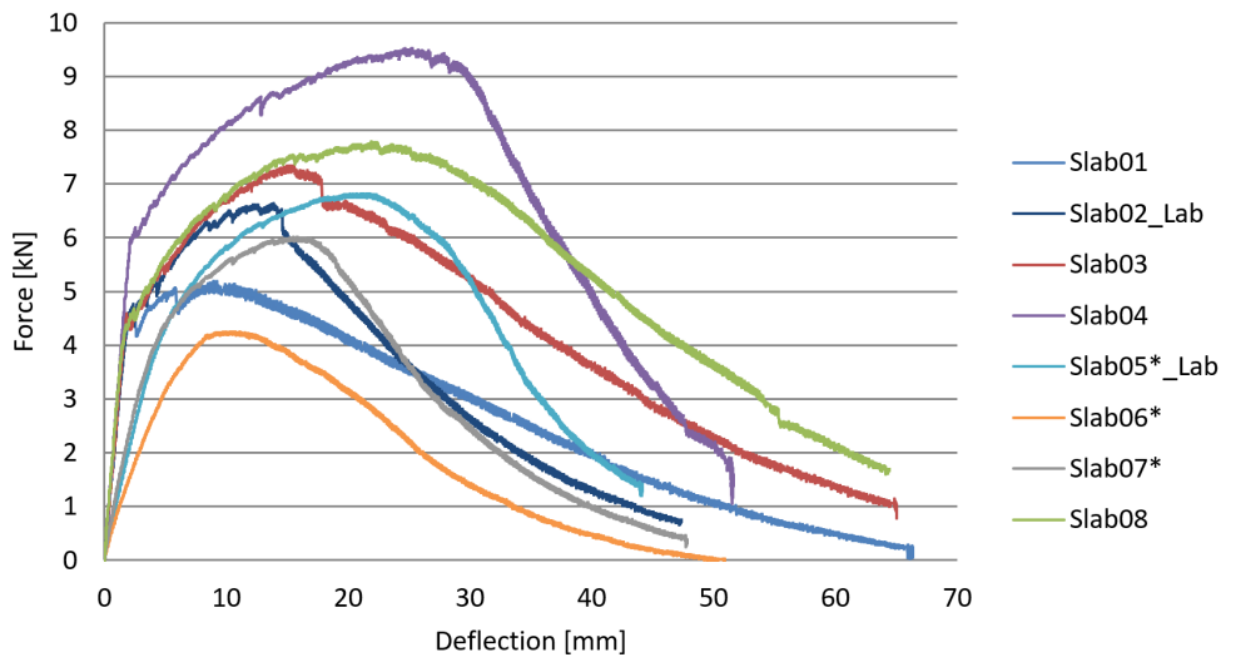

Fig. 4. Load-deflection diagram of tested undamaged and ballistic damaged slabs.

According to the load-deflection diagram (Fig. 4), for each specimen, the energy of fracture is divided into the energy dissipated during the strain-hardening $\left(G_{f A}\right)$ and the energy dissipated during the strain-softening $\left(G_{f B}\right)$, calculated as the area under the load-deflection curve. For undamaged slabs, $G_{f A}$ calculation starts from the point of first-peak where it is assumed that the specimen has lost its elastic behaviour under loading. Instead, for damaged slabs (Fig. 3), $G_{f B}$ calculation starts from the beginning of the loading since the specimens are already cracked. To make the slab's fracture energy more comparable, it is possible to normalize each energy of fracture per the corresponding crack's surface area and express the fracture energy in $\mathrm{kJ} / \mathrm{m}^{2}$. The crack surface area was estimated from the real crack development of each single UHPFRC plate. It was also confirmed that fibres were pulled out from the matrix and no rupture of the fibres was observed.

The flexural strength represents the highest stress experienced within the material just before the failure. In this sense, it is a strong indicator for the utilization of the element under loads, although it should be remembered the equation used is derived assuming a linear stress distribution (Table 2).

Table 2. Analyzed parameters.

\begin{tabular}{|c|c|c|c|c|c|c|c|c|}
\hline Status & \multicolumn{4}{|c|}{ Undamaged } & \multicolumn{3}{c|}{ *Damaged } \\
\hline $\begin{array}{c}\text { Casting } \\
\text { place }\end{array}$ & CTU lab & Ind. unit & Ind. unit & Ind. unit & Ind. unit & CTU lab & Ind. unit & Ind. unit \\
\hline Spec. & Slab02 & Slab01 & Slab03 & Slab04 & Slab08 & Slab05* & Slab06* & Slab07* \\
\hline $\begin{array}{c}\text { Peak- } \\
\text { Load } \\
{[\mathbf{k N ]}}\end{array}$ & 6.64 & 5.19 & 7.34 & 9.52 & 7.79 & 6.82 & 4.25 & 6.01 \\
\hline
\end{tabular}




\begin{tabular}{|c|c|c|c|c|c|c|c|c|}
\hline $\boldsymbol{G}_{f A}[\mathrm{~J}]$ & 68.33 & 31.64 & 78.26 & 175.30 & 132.69 & 109.59 & 31.06 & 70.25 \\
\hline $\boldsymbol{G}_{f B}[\mathbf{J}]$ & 79.73 & 132.38 & 163.62 & 114.96 & 149.04 & 65.03 & 68.27 & 75.32 \\
\hline $\boldsymbol{G}_{f_{-} \text {tot }}[\mathrm{J}]$ & 148.05 & 164.02 & 241.88 & 290.26 & 281.73 & 174.61 & 99.33 & 145.57 \\
\hline $\begin{array}{c}G_{f_{f} \text { norm }} \\
{\left[\mathrm{kJ} / \mathrm{m}^{2}\right]}\end{array}$ & 8.78 & 9.47 & 13.85 & 17.01 & 16.97 & 21.72 & 8.35 & 14.02 \\
\hline $\begin{array}{c}\sigma_{z}^{\max } \\
{[\mathrm{MPa}]}\end{array}$ & 13.06 & 10.23 & 14.46 & 18.75 & 15.34 & 13.43 & 8.38 & 11.82 \\
\hline
\end{tabular}

The large variance between the results can probably be caused by the non-uniform distribution of the fibres in the plate and by the varying orientation of fibres in the plate. Although we assume theoretically uniform dispersion and random orientation of the fibres, the result can be the aggregation of fibres into so-called nests and a high concentration of fibres in one place of the UHPFRC plate at the expense of other places. This can lead to a large scatter in flexural capacity and in a different course of load-deflection diagrams for equally reinforced elements.

In the case of the application of four-point bending, the plate is broken in the weakest place in the region of the maximum bending moment between the acting forces, and if there is a place with a lower fibre content in this space, the bending capacity is significantly reduced.

\section{Conclusions and further outlook}

The experimental campaign aimed to test the flexural capacity of thin plates made of UHPFRC and to determine the load-deflection diagram of these plates in flexure. In comparison with the reference undamaged plates, the work aimed to determine the bending capacity of the overall perforated plates, which were significantly damaged by the impact of the projectile. It was experimentally verified that such damaged plates are still able to provide a significant part of their flexural capacity and thus, for the most part, fulfil their load-bearing function. This is a significant advantage over elements reinforced with conventional concrete rebar, which is usually laid in a $100 \mathrm{~mm}$ to $150 \mathrm{~mm}$ grid and does not provide any significant effect against projectile penetration or damage. When using fibre reinforcement, the damage caused by the impact of the projectile is closely concentrated in a limited area. Due to the higher localization of the damage, the affected element can further transfer a significant part of its original flexural capacity.

An important moment is the correct orientation of the fibres in the body of the cementitious composite and its even distribution in the thin element. Even more favourable results could be expected with the controlled orientation of the fibres. To this end, the results of this experimental campaign may serve as reference values and will be compared in the next stage of research on thin elements, where the fibres will be oriented using an electromagnetic field [5].

The authors gratefully acknowledge the financial support from the Czech Science Foundation (grant number GA20-00624S). The authors also acknowledge assistance from students and technical staff at the Experimental Centre of the CTU who participated in the project.

\section{References}

1. R. Sovják, J. Rašínová, \& P. Máca, Acta Polytechnica, 54 (2014) 358-362.

2. J. Fornůsek, V. Jelínek, M. Mára, R. Sovják, \& J. Zatloukal, Ballistic panel and ballistic system, US 10,648,780 B2, 2020.

3. P. Konrád \& R. Sovják, International Journal of Protective Structures, 10 (2019) 
$251-265$.

4. H. Y. Grisaro \& A. N. Dancygier, International Journal of Impact Engineering, 116 (2018) 51-64.

$5 . \quad$ R. Lovichová, K. Takáčová, K. Künzel, V. Papež, M. Mára, J. Fornůsek, P. Konrád, \& R. Sovják, High Performance and Optimum Design of Structures and Materials IV, I (2020) 39-49.

6. Zezulova, E., Hasilova, K., Dvorak, P., Dubec, B., Komarkova, T-, Stoller, J. Experimental Campaign to Verify the Suitability of Ultrasound Testing Method for Steel Fiber Reinforced Concrete Fortification Structures. APPLIED SCIENCES-BASEL, 11 (18) Article Number8759, DOI 10.3390/app11188759, (2021)

7. Stoller, J. and Dvorak, P. Non-Destructive Testing of Full-Scale Slabs Before and after Blast Load, TRANSPORT MEANS - PROCEEDINGS OF THE INTERNATIONAL CONFERENCE, pp. 298-301 (2015)

8. Stoller, J. and Zezulova, E. The Field Testing of High Performance Fiber reinforced Concrete Slabs under the TNT Load Explosion together with the Analytical Solution and the Numerical Modelling of those Tests Results. INTERNATIONAL CONFERENCE ON MILITARY TECHNOLOGIES, pp.211-218 (2015)

9. Papán, D., Papánová, Z. Higher frequency dynamic response analysis of the foam concrete block element, MATEC Web of Conferences 196,01037 (2018) 